\title{
Gut Microbiota as a Target in the Pathogenesis of Metabolic Disorders: A New Approach to Novel Therapeutic Agents
}

Authors

Affiliations

\section{H.-S. Ejtahed ${ }^{1}$, A.-R. Soroush ${ }^{1}$, P. Angoorani ${ }^{1}$, B. Larijani ${ }^{2}$, S. Hasani-Ranjbar ${ }^{1,2}$}

Obesity and Eating Habits Research Center, Endocrinology and Metabolism Molecular-Cellular Sciences Institute, Tehran University of Medical Sciences, Tehran, Iran

Endocrinology and Metabolism Research Center, Endocrinology and Metabolism Clinical Sciences Institute,

Tehran University of Medical Sciences, Tehran, Iran
Key words

gut microbiota

- obesity

- diabetes

- osteoporosis

received 11.12 .2015

accepted 20.04.2016

Bibliography

DOI http://dx.doi.org/

10.1055/s-0042-107792

Published online:

May 20, 2016

Horm Metab Res 2016;

48: 349-358

(c) Georg Thieme Verlag KG

Stuttgart · New York

ISSN 0018-5043

Correspondence

\section{S. Hasani-Ranjbar}

Endocrinology and Metabolism

Research Institute (EMRI)

$5^{\text {th }}$ Floor, Shariati Hospital

North Kargar Ave

1411413137 Tehran

Iran

Tel.: + 98/21/88220037

Fax: + 98/21/88220 052

Sh_hasani@sina.tums.ac.ir

shirinhasanir@yahoo.com

\section{Abstract}

$\nabla$

As the prevalence of metabolic disorders increases dramatically, the importance of identifying environmental factors affecting metabolism control becomes greater accordingly. Gut microbiota, a complex ecosystem inhabiting the human gastrointestinal tract, is one of these potential factors. Recently, the evidence has shown the associations between alteration in gut microbiota composition and obesity, diabetes, and osteoporosis. However, the causality of gut microbiota on metabolic health has yet to be explored in interven-

\section{Introduction}

\section{$\nabla$}

The prevalence of metabolic disorders is increasing worldwide, leading to recognize them as public health concerns. The most prevalent metabolic disorders are diabetes mellitus, obesity, and osteoporosis. The involvement of both genetic and environmental factors makes the pathophysiologies of these disorders complicated. Gut microbiota is suggested as a potential contributor to the development of metabolic disorders in recent years $[1,2]$.

Gut microbiota is defined as the microbial community inhabiting the intestine; and gut microbiome are its genomic contents, which are 100- to 150-fold more numerous than the human genome [3]. These microbes, as an endocrine organ, play important roles in human health and their imbalances are related to numerous diseases such as inflammatory bowel disease, cardiovascular diseases, allergies, and metabolic disorders. Recent evidence in mice and humans has shown that gut microbiota is linked with the development of metabolic disorders [1,4-6].

Although only limited species of gut microbiota could be cultured by conventional culture techniques [7], advances in next generation sequenc- tion studies and the underlying mechanisms need to be investigated more in depth. Gut microbiota plays critical roles in the control of immunity, food intake, lipid accumulation, production of short chain fatty acids, insulin signaling, and regulation of bone mass. The gut microbiota represents a novel potential therapeutic strategy for the treatment of metabolic disorders. In this review, we provide insights into the role of the gut microbiota in metabolic disorders and its modulating interventions such as prebiotics, probiotics, and fecal microbiota transplantation.

ing and its metagenomic applications allowed the study of the microbiota composition in metabolic disorders without cultivation [8]. Results of the human microbiome studies, which are part of the human genome projects could have possible clinical applications like personalized medicine in the future [8]. It is noteworthy that despite the inter-individual variations in gut microbiota, serial stool collections have shown that core gut microbiota composition of an individual remains stable over time. Therefore, susceptibility to the development of specific diseases was different among subjects. The composition of the gut microbiota is modulated by prenatal events, delivery methods, infant feeding, duration of lactation, complementary foods, geographical location, and environmental factors such as life style, antibiotic use, and dietary pattern [9]. It seems that these factors, effective in altering gut microbiota composition, can be used for therapeutic purposes.

In this review, the mechanisms by which the gut microbiota may affect host metabolism are considered, and the methods of gut microbiota modulation as novel therapeutic strategies in metabolic disorders including obesity, diabetes, and osteoporosis are provided, as well. 


\section{Gut Microbiota and Obesity}

$\nabla$

\section{Role of gut microbiota in obesity}

Due to the epidemic spread of obesity all over the world and the complications related to weight gain in public health, gut microbiota have gained a growing interest as an environmental factor that may affect the possibility of obesity $[10,11]$. Increased energy intake and decreased physical activity are the main causes of obesity. In addition, various gene polymorphisms have been identified to have role in the pathogenesis of obesity $[12,13]$. Moreover, different factors such as specific proteins in human cells and many hormonal factors have effective roles in regulating metabolic homeostasis and weight balance [14-17]. Microbiota also has been taken into consideration as a possible reason for affecting energy homeostasis. It was suggested that gut microbita with environmental predisposition can lead to obesity through stimulating the development of impairment in energy homeostasis [18]. Numerous explorations have turned to the intestinal microbiota's contribution to obesity followed by exploring the first evidence of the link between obesity and intestinal microbiota $[19,20]$. Animal studies have indicated that microbiota leads to changing the production or secretion of molecules that affect both energy balance and energy stores (fat mass) [21,22]. Bacteroidetes (Gram-negative) and Firmicutes (Gram-positive) are the main phyla of gut bacteria. Firmicutes with more than 200 genera has the highest proportion as the most important of which are: Mycoplasma, Bacillus, and Clostridium. Firmicutes (60-65\%), Bacteroidetes (20-25\%), Proteobacteria (5-10\%), and Actinobacteria (3\%) together comprise about $97 \%$ of the gut microbiota $[23,24]$. On the other hand, Arumugam et al. suggested that the microbiota of most individuals could be categorized into 3 dominant enterotypes characterized as Bacteroides, Prevotella, and Ruminococcus, which are independent of age, gender, ethnicity, or body mass index $[23,25]$. Bacteroidetes and Firmicutes are 2 main groups of gut microbiota, whose proportion is changed in obese mice [19]. Administration of "western diet" to mice resulted in increased abundance of bacteria of the phylum Firmicutes and decreased abundance of bacteria of the phylum Bacteroidetes [26,27]. Human studies have also evaluated the gut microbiota in obese individuals and have documented a reduction in Bacteroidetes accompanied by a rise in Lactobacillus species belonging to the Firmicutes phylum in obese subjects $[28,29]$. On the other hand, some human studies have found different patterns in these alterations, such as the increase in species of both Bacteroidetes and Firmicutes in overweight women [30] or a decrease in Bacteroidetes with no differences in Firmicutes phylum in obese individuals [31]. Finally some studies have shown no difference between Bacteroidetes (B) and Firmicutes (F) at the phylum level [32-35]. Therefore, the $\mathrm{F} / \mathrm{B}$ ratio could not be used as an informative biomarker in distinguishing obese from nonobese individuals. The earlier studies in this field have focused on microbiota changes in phyla proportion. In recent years, novel next generation sequencing technology based on the analysis of the 16SrRNA bacterial gene allowed for the identification of the bacteria that colonize our gut in the species level. In a recent case-control study in obese and normal weight school-aged children, the relative abundance of bacterial and fungal gut microbes was evaluated. Obese children revealed a significantly lower abundance in Akkermansia muciniphyla, Faecalibacterium prausnitzii, Bacteroides/Prevotella group, Candida spp., and Saccharomyces spp. compared to normal-weight children [36].
Recent studies reveal that Lactobacillus spp. and bifidobacterium spp., which are the main bacterial population of the small intestine are not all the same and they may have different characteristics according to the species. For example, within the genus Lactobacillus, L. plantarum and L. paracasei are associated with leanness whereas L. reuteri is associated with obesity [37]. Drissi et al. have revealed that weight gain-associated Lactobacillus spp. appears to have limited ability in the catabolism of fructose or glucose and might reduce ileal brake effects. Whereas the weight protection-associated Lactobacillus spp. have developed defense mechanisms for enhanced glycolysis and defense against oxidative stress [38]. In a recent animal study, Lactobacillus sakei OK67 ameliorated high-fat diet-induced obesity in mice by inhibiting gut microbiota lipopolysaccharide production and nuclear factor-kB activation and inducing colon tight junction protein expression [39].

Some studies have reported that Akkermansia muciniphila has been founded at a lower concentration in obese individuals. This kind of gut species has potentially protective effects against obesity, metabolic conditions, inflammation, and insulin resistance. So it is a good candidate for consideration as a probiotic [40].

Using the Shannon index, species diversity within the gut has been reported to be lower in obese subjects [41]. However, it should be noted that metagenomic studies nowadays often rely on matching bacterial DNA sequences to reference databases, and these existing sequence databases could accordingly miss important unrecognized bacteria.

Germ-free mice transplanted with the microbiome from obese donors gained significantly more weight compared to germ-free mice transplanted with the microbiome from lean donors, which implies a causal role for the microbiome in obesity and weight gain [19]. However, the contribution of gut microbiota to obesity in humans is unclear and more human studies are needed to evaluate the species level and their changes to reveal the gut microbiota composition and modulation as novel diagnostic or therapeutic strategies to treat obesity and related complications. Major issues while comparing the results of different human studies of intestinal microbiota are potential confounders and some existing technical differences including differences in taxonomy database, taxonomy assignment algorithm, DNA extraction protocols, and PCR primers [41]. Moreover, potential confounding effects of diet, previous use of antibiotics, age, gender, and smoking status on microbiota composition and function should be controlled in obesity-related microbiome studies [42].

\section{Underlying mechanisms in obesity}

The gut micobiota might affect energy balance in human through several mechanisms. Fermentation of indigestible dietary compounds serves as an energy source to the host and plays a critical role in releasing of satiety hormones $[43,44]$. The possible effect of gut microbiota is associated with producing shortchain fatty acids (SCFAs) through fermentation of dietary fiber [45]. The major microbiotic phyla affecting SCFA production in the gut are Firmicutes and Bacteroidetes, as well as the minor phyla Melainabacteria [45]. SCFAs, especially butyrate significantly increases plasma levels of gastric inhibitory peptide (GIP), glucagon-like peptide 1 (GLP-1), peptide YY (PYY), insulin, and amylin, which would have a net effect on slowing digestion and nutrient intestinal transit, promoting satiety, and increasing plasma insulin. Acetate is reported to increase leptin released by fat cells; propionate increases G-protein mediated secretion of 
PYY and GLP-1 in the gut and controls the rates of lipolysis and lipogenesis in fat cells $[46,47]$.

Gut microbiota can facilitate the extraction of calories from ingested dietary substances through increasing the absorption of monosaccharides from the gut [19]. Carbohydrate response element-binding protein (ChREBP) and liver sterol response element-binding protein type-1 (SREBP-1) were demonstrated to be involved in the absorption of monosaccharides in the intestine and hepatic lipogenesis induced by the gut microbiota [48]. The other mechanism is the central effect of gut microbiota on leptin signaling [49-51]. The mice with a mutation in the leptin gene (metabolically obese mice) have different microbiota compared with other mice without the mutation [20]. Germ-free mice have significantly increased antiobesity molecule GLP-1 and also reduced anorexigenic brain-derived neurotrophic factor (Bdnf), and leptin resistance associated suppressor of cytokine signaling 3 (Socs3) expressions in both the brainstem and hypothalamus, in comparison with conventionally raised mice. As a consequence, the suppression of any of these molecules by microbes leads to weight gain [49].

Considering the chronic low grade inflammation state in obesity, a new hypothesis has been proposed correlating intestinal flora and obesity. In high-fat diet animal models, the inflammation that leads to diabetes and obesity has been suggested to be triggered by the lipopolysaccharides (LPS) of gram-negative bacteria [52]. Increase in the uptake of LPS and the permeability of the intestine leads to a systemic inflammation [53]. Everard et al. have shown that microflora bacteria interacting with the mucus layer may have a critical effect on obesity [40]. Another mechanism involved in weight control by intestinal microbiota is regulation of fasting-induced adipose factor (FIAF) expression. FIAF is a protein produced by enterocyte, which has an inhibitory effect on lipoprotein lipase (LPL). Unbalanced gut microbiota can suppress FIAF expression and increase LPL activity and triglyceride accumulation in adipose tissue [54] (• Fig. 1).

\section{Modulation of gut microbiota in obesity}

Studies have indicated that the microbiota composition can be affected by external disturbances such as diet, disease, and environment $[55,56]$. Dietary changes could lead to $57 \%$ of the total structural variation in gut microbiota whereas changes in genetics explain no more than $12 \%$ [57]. Prebiotics and probiotics are examples of dietary manipulation of the gut microbiota. Probiotics are defined as "live microorganisms that their administration in adequate amounts causes health benefits on the host' [58]. The most commonly used probiotic microorganisms have been the following genera: Lactobacillus, Bifidobacterium, Saccharomyces, Enterococcus, Streptococcus, Pediococcus, Leuconostoc, and Bacillus. However, as probiotic properties have been shown to be strain specific, identification of particular strains is very important. On the other hand, it is also demonstrated that probiotics are safe and beneficial for healthy individuals, caution in selecting of probiotics for immunocompromised patients or patients with a leaky gut is needed [59].

A prebiotic is an ingredient that its fermentation leads to beneficial changes in the gut microbiota [60]. There is evidence that rise in Bifidobacterium spp. produced by some prebiotics is accompanied by an increase in GLP1 and PYY secretion by the intestine. These 2 molecules have favorable effects on insulin resistance and the functionality of beta cells [61-63]. In addition, the modulation of gut microbiota with prebiotics increases GLP2 production in the colon, which is associated with higher expression of zonula occludens-1 (ZO-1), tight junction protein, that decrease plasma LPS through improving the mucosal barrier function $[63,64]$. Various compounds including lactulose, lactitol, galacto-oligosaccharides, fructo-oligosaccharides, inulin, isomalto-oligosaccharides, polydextrose, resistant starch and gums can act as prebiotic [65]. Metagenomics studies could be helpful to assess the concept of prebiotic activity of different compounds. Studies on the prebiotic effect of various dietary fiber and polyphenols food sources are being conducted.

Fecal microbiota transplantation (FMT), a method that transfers intestinal bacteria from a healthy donor into a patient, is also considered as an important "physiologic" factor in the prevention and treatment of metabolic dysregulation. This method may be effective in improving the obesity, insulin resistance, and metabolic syndrome [66]. FMT from lean donors to individuals with metabolic syndrome significantly increased insulin sensitivity, fecal butyrate concentrations, microbial diversity, and the relative abundance of bacteria related to the butyrate-producing Roseburia intestinalis [67]. The effects of FMT on weight control, however, needs to be explored in future clinical trials and it should be noted that like all personalized medicines, some interventions may not only be ineffective in controlling an individual's obesity, they may even be an additional risk factor.

\section{Gut Microtobia and Diabetes}

\section{$\nabla$}

\section{Role of gut microbiota in diabetes}

Changes in the gut microbiota were observed during the lifespan from infancy to elderly $[68,69]$. Different factors that influence these alterations can lead to metabolic disorders such as diabetes. For instance the gut microbiota of babies born vaginally is similar to their mothers, but those delivered by caesarean section have delayed microbial colonization by Bacteroides, Bifidobacterium, and Lactobacillus. Therefore, the incidence of type 1 diabetes mellitus (T1DM) has been noted to occur more frequently in them $[70,71]$. Studies in children with a high genetic risk for type 1 diabetes revealed significant differences in the gut microbiota between children who developed autoimmunity and those who remained healthy. In these children strong association between Bacteroides dorei and type 1 diabetes was discovered. Therefore, increase in Bacteroides dorei abundance may be useful for predicting T1D autoimmunity in genetically susceptible infants [72].

Alteration of gut microbiota composition has been also observed in type 2 diabetes mellitus (T2DM). Studies have indicated that there is a significant reduction of Firmicutes and Clostridia, while the relative proportion of Bacteroidetes and Betaproteobacteria increases in type 2 diabetic patients compared with the healthy persons [5]. Recent studies demonstrated that disrupted mucus-bacterial interactions might be contributing to gut dysbiosis and inflammation. Artificial sweeteners and 2 commonly used emulsifiers including carboxymethylcellulose and polysorbate-80, which were components of processed foods, induced adiposity and glucose intolerance/metabolic syndrome via altering gut microbiota composition [73,74].

Animal studies showed that transplantation of gut microbiota from conventionally raised obese mice to germ-free mice leads to a significant increase in body fat content and insulin resistance in recipient mice $[19,75]$. Some studies showed significantly higher levels of Lactobacillus species and lower levels of Clostridium species in the T2DM group [76,77]. Moreover, the 


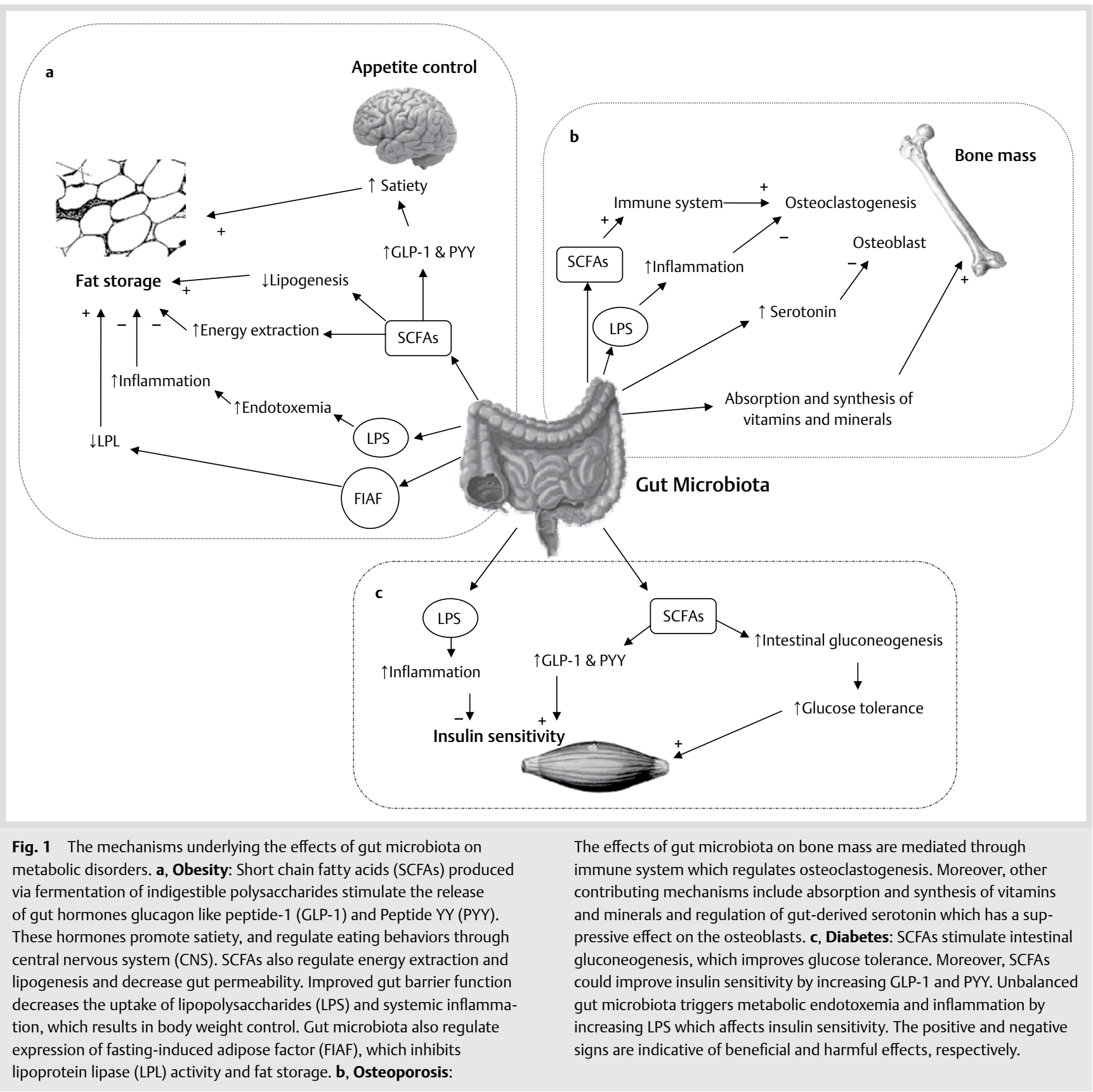

abundance of Bifidobacterium decreases in obese individuals and T2DM patients [78]. Researchers have identified 47 metagenomic linkage groups in the T2DM-associated gene markers from the gut metagenome. They indicated that the abundance of butyrate-producing Clostridiales including Roseburia and Faecalibacterium prausnitzii, which have a protective role against T2DM, decreased significantly in patients with T2DM but the proportion of Clostridiales that do not produce butyrate increased [76]. Zhang et al. revealed that patients with T2DM have increased the proportion of Firmicutes and Clostridia in comparison with healthy individuals, and the level of Betaproteobacteria increased significantly in the prediabetes and T2DM [79]. Therefore, special gut bacterial strains may act as early diagnostic markers for identification of subjects at risk of T2DM.

\section{Underlying mechanisms in diabetes}

The possible mechanisms through which gut microbiota is associated with obesity may be related to diabetes as well. One of these mechanisms is the essential role of the gut microbiota in the fermentation of indigestible dietary polysaccharides into SCFAs that act as regulators of food or energy intake and inflammation $[80,81]$. SCFAs, acetate, propionate, and butyrate, bind to G protein-coupled receptors (GPCRs) such as GPR41 and GPR43, in the enteroendocrine cells [82]. SCFAs-mediated activation of GPR43 in the adipose tissue prevented fat accumulation by suppressing insulin signaling [83]. Moreover, activated GPR43 in the intestine could increase insulin sensitivity by stimulating the secretion of GLP-1 [84].

Since insulin resistance and T2DM are associated with low-grade inflammation, the inflammatory effective factors such as change in gut microbiota can be a possible mechanism for them $[85,86]$. Gut microbiota is full of molecules such as lipopolysaccharide 
(LPS) and peptidoglycan, which can lead to inflammation and related metabolic disorders [52]. Alteration in gut microbiota triggers metabolic endotoxemia and inflammation by LPS- and CD14/toll-like receptor (TLR) 4-dependent mechanisms [61]. LPS, lipids, fatty acids and chemokines stimulate c-Jun N-terminal kinase (JNK) and ІкB kinase (IKK)- $\beta$ pathways intracellularly. IKK $\beta$ activates family of nuclear factor (NF)-кB transcription factors and promotes the expression of many mediators of inflammation that can result in insulin resistance. JNK increases the phosphorylation of insulin receptor substrate (IRS)- 1 at serine sites and decreases normal signal transduction by the insulin receptor/IRS-1 axis, therefore this leads to insulin resistance [87]. Furthermore, tight junction proteins such as zonulaoccludens (ZO)-1 and occludin in intestinal epithelial cells reduce gut permeability and inflammatory markers and improve insulin resistance accordingly [88].

Dietary soluble fibers stimulate intestinal gluconeogenesis (IGN), which exert an antidiabetic effect contrary to the general idea that gluconeogenesis impairs glucose tolerance [89]. The expression of IGN gene is stimulated by butyrate through a cAMP-dependent mechanism, but propionate activates IGN gene expression through a gut-brain axis [89]. The IGN released glucose signals the brain by the peripheral nervous system and exerts beneficial effects on dietary intake and glucose tolerance [90] (० Fig. 1).

\section{Modulation of gut microbiota in diabetes}

The modulation of gut microbiota is a novel therapeutic strategy for glycemic control performed by known components such as prebiotics, probiotics, and some drugs like metformin. Probiotics may have antidiabetic effects due to the compositional changes of the intestinal microbiota [5]. Studies indicated that probiotic consumption led to a healthier gut microbiota and has been identified as an effective supplementary treatment in insulin resistance and its related complications [91,92]. Bifidobacteria and Lactobacilli are commonly used strains of probiotics in functional foods and dietary supplements [93]. Studies have indicated that the consumption of L. acidophilus, L. casei, L. lactis, and L. plantarum DSM15313 decreases the glycemic curve, insulin resistance, and HbA1c $[94,95]$. Marques et al. showed that $\gamma$-aminobutyric acid (GABA)-producing Lactobacillus brevis attenuated hyperglycemia in streptozotocin-induced type 1 diabetes rat models [96]. Probiotics may exert antidiabetic properties via immune-modulatory effects $[87,97,98]$. Further research is warranted into dosage magnitude, and mechanism of probiotics' effects [98].

Prebiotics, which are fermentable polysaccharides, promote SCFA production, stimulate the growth of beneficial bacteria such as Bifidobacterium, and improve gut barrier function [99]. Therefore, prebiotics improve gut permeability, decrease metabolic endotoxemia, reduce inflammation, and improve glucose intolerance $[51,64]$.

Metformin can also affect the gut microbiota. Shin et al. have demonstrated that metformin can increase the abundance of Akkermansia muciniphila, mucin-degrading bacteria, in the gut of mice fed a high fat diet. Therefore, metformin may exert its antidiabetic effects by modulation of the gut microbiota through increasing the Akkermansia muciniphila population [100]. Moreover, results of in vitro study investigated the effects of acarbose on ruminal fermentation characteristics and the composition of the microbiota revealed that the proportion of Firmicutes and Proteobacteria was decreased and the percentage of Bacteroi- detes, Fibrobacteres, and Synergistetes was increased in acarbose group compared with the control group. This study documented that acarbose could be useful for preventing the accumulation of LPS in the rumen [101].

Recent articles indicated the fecal microbiota transplantation as a new potential therapeutic option in T2DM. Vrieze et al. reported that fecal microbiota transplantation from lean donors to obese subjects with metabolic syndrome increased butyrateproducing bacteria and improved insulin sensitivity [67]. In future, well-designed trials are needed to develop a new treatment for diabetes.

\section{Gut Microbiota and Osteoporosis}

$\nabla$

\section{Role of gut microbiota in osteoporosis}

Osteoporosis, a major bone health concern, could result in a huge economic burden on health care systems. The bone health depends both on how much bone is acquired until peak bone mass is attained at 20-30 years of age and on the rate of the subsequent bone loss. Hereditary and environmental factors are major determinants of the variances in peak bone mass and agerelated bone loss $[102,103]$. The potential of gut microbiota to affect bone health is a rather new area of investigation. Recent evidences have demonstrated gut microbiota as a regulator of bone mass mediated through effects on the immune system [6]. Unbalanced microbial composition of the gut microbiota has been suggested to be involved in different inflammatory diseases, within and outside the gastrointestinal tract, including inflammatory bowel diseases, rheumatoid arthritis, allergies, obesity, and metabolic syndrome [104,105]. Moreover, inflammatory and autoimmune conditions have been associated with low bone mass, suggesting the relationship between the immune system and bone metabolism [106].

Bone-forming osteoblasts and bone-resorbing osteoclasts are responsible for bone remodeling. The skeleton provides hematopoietic stem cells, which differentiate into osteoclasts or immune cells ( $\mathrm{T}$ cells) depending on local microenvironment status [107]. Evidences indicate that low-grade inflammation affects bone turnover and subsequently bone mass [108]. Therefore, it was suggested that gut microbiota, which is correlated with immune system, could work as a regulator of bone mass and a new gut microbiota-bone research field, known as osteomicrobiology was proposed.

The germ-free mouse is a useful model to study the effects of gut microbiota on bone mass. Sjogren et al. demonstrated that the absence of gut microbiota in germ-free mice was associated with increased bone mass. It was found that bone marrows of germ-free mice have fewer $\mathrm{CD} 4+\mathrm{T}$ cells and osteoclast precursors compared to conventionally raised mice. These fewer CD4+ $\mathrm{T}$ cells in bone marrows are caused by fewer $\mathrm{CD} 4+\mathrm{T}$ cells recirculating in the blood and secondary lymphoid tissue resulting in a decreased expression of inflammatory cytokines [6].

As human grows older, osteoporosis become more prevalent, in a way that one in 3 women and one in 5 men experience osteoporotic fracture after the age of 50 [109]. Although gut microbiota varies widely among individuals, there are significant changes in gut microbial composition of older adults. Gut microbiota shift from obligate anaerobes to facultative anaerobes in the elderly, leading to inflammation. Gut microbiota in older adults have higher amounts of pathogenic Proteobacteria and Bacilli and lower amounts of anti-inflammatory Lactobacilli 
[110]. Evidence indicated that as elderly move from living in the community to long-term care facilities, large microbial changes occurred in their gut microbiota [111]. These changes alter bone and body composition and increase the risk of osteoporosis.

It seems that the analysis of the gut microbiota composition in osteoporotic subjects could evaluate the possible associations between bone mineral density and specific bacterial phyla, genera, and specious. Moreover, the analysis of the gut microbiota composition in cohort studies can be used to determine the predictive role of the gut microbiota for low bone mass and osteoporotic fractures risk.

\section{Underlying mechanisms in osteoporosis}

It was proposed that the most probable mechanism by which gut microbiota affects bone mineral density involves the immune system, which in turn regulates osteoclastogenesis [108]. Moreover, SCFAs could regulate inflammation and possibly exerts their direct effects on bone [112]. Direct effect of butyrate on bone cells was the inhibition of osteoclast formation. Furthermore, it was found that SCFAs could regulate osteoclastogenesis indirectly through affecting on T cells in the colon [112]. In addition to osteoclastogenesis suppression, gut microbiota enhance absorption and synthesis of various vitamins and minerals including vitamins $\mathrm{K}$ and $\mathrm{B} 12$, calcium, and magnesium, which increase bone density and strength [109,113]. The effects of prebiotic and probiotic supplementation on gut microbiota composition and mineral absorption needs to be further investigated. Although, it should be considered that how precise could the fecal microbiome composition reflect the microbiome of intestinal active site for mineral absorption.

Studies have shown that gut microbiota also can influence bone mass by the neurotransmitter serotonin. Several microbial species directly synthesize serotonin, some others, however, regulate the availability of tryptophan as a serotonin precursor. Serotonin has a suppressive effect on osteoblast and may control bone mass via this pathway [114-116] (० Fig. 1).

\section{Modulation of gut microbiota in osteoporosis}

The microbiota composition of osteoporotic subjects could be modulated by dietary manipulation like prebiotics and probiotics. Prebiotic supplementation in animal models altered gut microbiota in favor of bifidobacteria and increased short chain fatty acids, and improved mineral absorption and bone density as well $[113,117]$.

Studies have shown that different Lactobacillus strains, including $L$. reuteri, $L$. paracasei, and $L$. plantarum supplementation suppressed bone loss in ovariectomized mouse models $[118,119]$. Therefore, it was proposed that the gut microbiota composition could be involved in the bone loss experienced by postmenopausal women who lose the immunosuppressive effects of estrogen. Lactobacillus reuteri also decreased intestinal inflammation and increased bone density in healthy male mice and type 1 diabetic mice $[120,121]$. Moreover, yacon flour in combination with $B$. longum, as a synbiotic food, helped to increase the concentration of minerals in the bones of rats [122]. Taken together, as certain probiotic bacteria may benefit bone and others may harm bone by promoting inflammation, future randomized clinical trials are needed to assess the possible effects of probiotic and prebiotic supplementation on bone health.

\section{Conclusion and Future Perspectives \\ $\nabla$}

From the grounds up, the development of new strategies for prevention and control purposes for the rapid spreading of metabolic disorders are critical. Recent studies implicate that metabolic phenotypes are associated with altered intestinal microbiota composition compared to healthy counterparts. However, most of the published human studies are associative and causality of gut microbiota in metabolic disorders should be investigated in further research in order to allow using gut microbiota modulation as a target for preventing or treating human metabolic disorders. Integration of gut metagenomics studies with other high-throughput techniques like metabolomics can expand our knowledge of the gut microbiota-host interactions and will discover underlying cellular and molecular mechanisms involved in metabolic health. Apprehending the role of gut microbiota in the modulation of host metabolism can provide novel therapeutic strategies. Future studies to identify specific bacterial species associated with metabolic phenotypes can help in providing therapeutic solutions by modulating the gut microbiota.

The ways through which the modulation of intestinal microbiota might be achieved include dietary intervention using prebiotics and probiotics or microbial transplantation from healthy donors. Administrations of prebiotics, as a dietary method of gut microbiota modulation, resulted in an increase in the lactobacillus and bifidobacterium species and also a dose-dependently increase in the satiety hormones levels including GLP-1 and PYY. Studies are ongoing to select the best type of prebiotics with beneficial effects on metabolic health. Furthermore, as many medicinal plants are used for the treatment of metabolic disorders throughout the world whose effects may be linked to the modulation of gut microbiota, prebiotic properties of these herbal medicines should be investigated [123-125].

Moreover, the selection of new probiotic strains including Faecalibacterium prausnitzii, Akkermansia muciniphila, and Bacteroides uniformis, which efficiently modulate the human gut microbiome in preclinical trials is a new strategy to improve metabolic disorders [126].

Fecal microbiota transplantation (FMT) has been demonstrated to alter the gut microbiota of the recipient. Ongoing placebocontrolled trials are being conducted in humans to examine if microbiota transplantation can improve metabolic health. Fecal transplantation studies might reveal the causality relationship between specific intestinal bacterial strains and metabolic health. However, critical issues including host immune response, determination of suitable donors, and preparation of donor samples before treatment should be considered in FMT.

Regarding the primary driving sources of metabolic disorders, investigating the gut microbiota composition in genetic variants of metabolic disorders could be effective in order to implement more personalized treatment. Although the association between gut microbiota and obesity-related metabolic abnormalities has been shown in recent studies, a proportion of obese individuals are free of metabolic abnormalities. The mechanisms underlying this protective profile of the metabolically healthy obese are not known. On the other hand, metabolically nonobese individuals are a subgroup of normal weight subjects with a variety of obesity-related co-morbidities. Future studies are needed to investigate the differences in microbiota composition between these different metabolic phenotypes. This knowledge can result in new therapeutic areas in the field of obesity and metabolic 
disorders. Moreover, osteosarcopenic obesity, the concurrent appearance of obesity and low bone and muscle mass is a condition whose etiological studies are limited. Evaluating the gut microbiota composition in this condition could be useful for developing a new strategy to improve the health outcomes.

\section{Conflict of Interest}

$\nabla$

There is no potential conflict of interest relevant to this article.

\section{References}

1 Brahe LK, Le Chatelier E, Prifti E, Pons N, Kennedy S, Hansen T, Pedersen $O$, Astrup A, Ehrlich SD, Larsen LH. Specific gut microbiota features and metabolic markers in postmenopausal women with obesity. Nutr Diabetes 2015; 5: e159

2 Mohammed A, Guda C. Application of a hierarchical enzyme classification method reveals the role of gut microbiome in human metabolism. BMC Genomics 2015; 16 (Suppl 7): S16

3 Tremaroli $V$, Backhed $F$. Functional interactions between the gut microbiota and host metabolism. Nature 2012; 489: 242-249

4 Vijay-Kumar M, Aitken JD, Carvalho FA, Cullender TC, Mwangi S, Srinivasan S, Sitaraman SV, Knight R, Ley RE, Gewirtz AT. Metabolic syndrome and altered gut microbiota in mice lacking Toll-like receptor 5. Science 2010; 328: 228-231

5 Larsen N, Vogensen FK, van den Berg FW, Nielsen DS, Andreasen AS, Pedersen BK, Al-Soud WA, Sorensen SJ, Hansen LH, Jakobsen M. Gut microbiota in human adults with type 2 diabetes differs from nondiabetic adults. PLoS One 2010; 5: e9085

6 Sjogren K, Engdahl C, Henning P, Lerner UH, Tremaroli V, Lagerquist MK, Backhed $F$, Ohlsson $C$. The gut microbiota regulates bone mass in mice. J Bone Miner Res 2012; 27: 1357-1367

7 Sharma P, Kumari H, Kumar M, Verma M, Kumari K, Malhotra S, Khurana J, Lal R. From bacterial genomics to metagenomics: concept, tools and recent advances. Indian J Microbiol 2008; 48: 173-194

$8 \mathrm{Kim} \mathrm{BS}$, Jeon YS, Chun J. Current status and future promise of the human microbiome. Pediatr Gastroenterol Hepatol Nutr 2013; 16: 71-79

9 Kau AL, Ahern PP, Griffin NW, Goodman AL, Gordon JI. Human nutrition, the gut microbiome and the immune system. Nature 2011; 474: 327-336

10 World Health Organization. Obesity and overweight - Fact sheet N_311-updated March 2011. http://www.who.int/mediacentre/ factsheets/fs311/en/index.html

11 Jafari-Adli $S$, Jouyandeh $Z$, Qorbani $M$, Soroush A, Larijani $B$, Hasani-Ranjbar S. Prevalence of obesity and overweight in adults and children in Iran; a systematic review. J Diabetes Metab Disord 2014; 13: 121

12 Tabatabaei-Malazy O, Hasani-Ranjbar S, Amoli MM, Heshmat R, Sajadi $M$, Derakhshan R, Amiri P, Namakchian M, Rezazadeh E, TavakkolyBazzaz J, Keshtkar A, Larijani B. Gender-specific differences in the association of adiponectin gene polymorphisms with body mass index. Rev Diabet Stud 2010; 7: 241-246

13 Tavakkoly Bazzaz J, Shojapoor M, Nazem H, Amiri P, Fakhrzadeh H, Heshmat R, Parvizi M, Hasani Ranjbar S, Amoli MM. Methylenetetrahydrofolate reductase gene polymorphism in diabetes and obesity. Mol Biol Rep 2010; 37: 105-109

14 Ramdas M, Harel C, Armoni M, Karnieli E. AHNAK KO mice are protected from diet-induced obesity but are glucose intolerant. Horm Metab Res 2015; 47: 265-272

15 Martins CJ, Genelhu V, Di Marzo V, Francischetti EA. The endocannabinoid system--back to the scene of cardiometabolic risk factors control? Horm Metab Res 2014; 46: 529-536

16 Lv J, Pan Y, Li X, Cheng D, Ju H, Tian J, Shi H, Zhang Y. Study on the distribution and elimination of the new hormone irisin in vivo: new discoveries regarding irisin. Horm Metab Res 2015; 47: 591-595

17 Almario RU, Karakas SE. Roles of circulating WNT-signaling proteins and WNT-inhibitors in human adiposity, insulin resistance, insulin secretion, and inflammation. Horm Metab Res 2015; 47: 152-157

18 Moreno-Indias I, Cardona F, Tinahones FJ, Queipo-Ortuno MI. Impact of the gut microbiota on the development of obesity and type 2 diabetes mellitus. Front Microbiol 2014; 5: 190

19 Turnbaugh PJ, Ley RE, Mahowald MA, Magrini V, Mardis ER, Gordon JI. An obesity-associated gut microbiome with increased capacity for energy harvest. Nature 2006; 444: 1027-1031
20 Ley RE, Backhed F, Turnbaugh P, Lozupone CA, Knight RD, Gordon JI. Obesity alters gut microbial ecology. Proc Natl Acad Sci USA 2005; 102: 11070-11075

21 Heimann E, Nyman M, Degerman E. Propionic acid and butyric acid inhibit lipolysis and de novo lipogenesis and increase insulin-stimulated glucose uptake in primary rat adipocytes. Adipocyte 2015; 4: 81-88

22 Chimerel C, Emery E, Summers DK, Keyser U, Gribble FM, Reimann F. Bacterial metabolite indole modulates incretin secretion from intestinal enteroendocrine L cells. Cell Rep 2014; 9: 1202-1208

23 Benson AK, Kelly SA, Legge R, Ma F, Low SJ, Kim J, Zhang M, Oh PL, Nehrenberg $D$, Hua K, Kachman SD, Moriyama EN, Walter J, Peterson $D A$, Pomp D. Individuality in gut microbiota composition is a complex polygenic trait shaped by multiple environmental and host genetic factors. Proc Natl Acad Sci U S A 2010; 107: 18933-18938

24 The Human Microbiome Project Consortium. Structure, function and diversity of the healthy human microbiome. Nature 2012; 486: 207-214

25 Arumugam M, Raes J, Pelletier E, Le Paslier D, Yamada T, Mende DR, Fernandes GR, Tap J, Bruls T, Batto JM, Bertalan M, Borruel N, Casellas F, Fernandez L, Gautier L, Hansen T, Hattori M, Hayashi T, Kleerebezem $M$, Kurokawa K, Leclerc M, Levenez F, Manichanh C, Nielsen HB, Nielsen T, Pons N, Poulain J, Qin J, Sicheritz-Ponten T, Tims S, Torrents D, Ugarte E, Zoetendal EG, Wang J, Guarner F, Pedersen O, de Vos WM, Brunak $S$, Dore J, Antolin M, Artiguenave F, Blottiere HM, Almeida M, Brechot C, Cara C, Chervaux C, Cultrone A, Delorme C, Denariaz G, Dervyn $R$, Foerstner KU, Friss C, van de Guchte M, Guedon E, Haimet F, Huber W, van Hylckama-Vlieg J, Jamet A, Juste C, Kaci G, Knol J, Lakhdari O, Layec $S$, Le Roux K, Maguin E, Merieux A, Melo Minardi R, M'Rini C, Muller $J$, Oozeer R, Parkhill J, Renault P, Rescigno M, Sanchez N, Sunagawa $S$, Torrejon A, Turner K, Vandemeulebrouck G, Varela E, Winogradsky $Y$, Zeller G, Weissenbach J, Ehrlich SD, Bork P. Enterotypes of the human gut microbiome. Nature 2011; 473: 174-180

26 Turnbaugh PJ, Ridaura VK, Faith JJ, Rey FE, Knight R, Gordon JI. The effect of diet on the human gut microbiome: a metagenomic analysis in humanized gnotobiotic mice. Sci Transl Med 2009; 1: 6ra14

27 Turnbaugh PJ, Hamady M, Yatsunenko T, Cantarel BL, Duncan A, Ley $R E$, Sogin ML, Jones WJ, Roe BA, Affourtit JP, Egholm M, Henrissat B, Heath AC, Knight R, Gordon JI. A core gut microbiome in obese and lean twins. Nature 2009; 457: 480-484

28 Ley RE, Turnbaugh PJ, Klein S, Gordon JI. Microbial ecology: human gut microbes associated with obesity. Nature 2006; 444: 1022-1023

29 Armougom F, Henry M, Vialettes B, Raccah D, Raoult D. Monitoring bacterial community of human gut microbiota reveals an increase in Lactobacillus in obese patients and Methanogens in anorexic patients. PLoS One 2009; 4: e7125

30 Collado MC, Isolauri E, Laitinen K, Salminen S. Distinct composition of gut microbiota during pregnancy in overweight and normalweight women. Am J Clin Nutr 2008; 88: 894-899

31 Furet JP, Kong LC, Tap J, Poitou C, Basdevant A, Bouillot JL, Mariat D, Corthier G, Dore J, Henegar C, Rizkalla S, Clement K. Differential adaptation of human gut microbiota to bariatric surgery-induced weight loss: links with metabolic and low-grade inflammation markers. Diabetes 2010; 59: 3049-3057

32 Duncan SH, Lobley GE, Holtrop G, Ince J, Johnstone AM, Louis P, Flint HJ. Human colonic microbiota associated with diet, obesity and weight loss. Int J Obes (Lond) 2008; 32: 1720-1724

33 Jumpertz R, Le DS, Turnbaugh PJ, Trinidad C, Bogardus C, Gordon JI, Krakoff J. Energy-balance studies reveal associations between gut microbes, caloric load, and nutrient absorption in humans. Am J Clin Nutr 2011; 94: 58-65

34 Mai V, McCrary QM, Sinha R, Glei M. Associations between dietary habits and body mass index with gut microbiota composition and fecal water genotoxicity: an observational study in African American and Caucasian American volunteers. Nutr J 2009; 8: 49

35 Kocelak P, Zak-Golab A, Zahorska-Markiewicz B, Aptekorz M, Zientara $M$, Martirosian G, Chudek J, Olszanecka-Glinianowicz M. Resting energy expenditure and gut microbiota in obese and normal weight subjects. Eur Rev Med Pharmacol Sci 2013; 17: 2816-2821

36 Borgo F, Verduci E, Riva A, Lassandro C, Riva E, Morace G, Borghi E. Relative Abundance in Bacterial and Fungal Gut Microbes in Obese Children: A Case Control Study. Child Obes 2016 Mar 23 [Epub ahead of print]

37 Million M, Maraninchi M, Henry M, Armougom F, Richet $H$, Carrieri $P$, Valero $R$, Raccah $D$, Vialettes $B$, Raoult $D$. Obesity-associated gut microbiota is enriched in Lactobacillus reuteri and depleted in Bifidobacterium animalis and Methanobrevibacter smithii. Int J Obes (Lond) 2012; 36: 817-825 
38 Drissi F, Merhej V, Angelakis E, El Kaoutari A, Carriere F, Henrissat B, Raoult $D$. Comparative genomics analysis of Lactobacillus species associated with weight gain or weight protection. Nutr Diabetes 2014; 4: e109

39 Lim SM, Jeong JJ, Woo KH, Han MJ, Kim DH. Lactobacillus sakei OK67 ameliorates high-fat diet-induced blood glucose intolerance and obesity in mice by inhibiting gut microbiota lipopolysaccharide production and inducing colon tight junction protein expression. Nutr Res 2016; 36: 337-348

40 Everard A, Belzer C, Geurts L, Ouwerkerk JP, Druart C, Bindels LB, Guiot $Y$, Derrien M, Muccioli GG, Delzenne NM, de Vos WM, Cani PD. Crosstalk between Akkermansia muciniphila and intestinal epithelium controls diet-induced obesity. Proc Natl Acad Sci U S A 2013; 110: 9066-9071

41 Walters WA, Xu Z, Knight R. Meta-analyses of human gut microbes associated with obesity and IBD. FEBS Lett 2014; 588: 4223-4233

42 Al-Ghalith GA, Vangay P, Knights D. The guts of obesity: progress and challenges in linking gut microbes to obesity. Discov Med 2015; 19: $81-88$

43 Guida S, Venema K. Gut microbiota and obesity: involvement of the adipose tissue. J Funct Foods 2015; 14: 407-423

44 Olli K, Salli K, Alhoniemi E, Saarinen M, Ibarra A, Vasankari T, Rautonen $N$, Tiihonen $K$. Postprandial effects of polydextrose on satiety hormone responses and subjective feelings of appetite in obese participants. Nutr J 2015; 14: 2

45 Rosenbaum $M$, Knight $R$, Leibel $R$. The gut microbiota in human energy homeostasis and obesity. Trends Endocrinol Metab 2015; 26: 493501

46 Kimura I, Inoue D, Hirano K, Tsujimoto G. The SCFA Receptor GPR43 and Energy Metabolism. Front Endocrinol (Lausanne) 2014; 5: 85

47 Inoue D, Tsujimoto G, Kimura I. Regulation of Energy Homeostasis by GPR41. Front Endocrinol (Lausanne) 2014; 5: 81

48 Backhed F, Ding H, Wang T, Hooper LV, Koh GY, Nagy A, Semenkovich $C F$, Gordon JI. The gut microbiota as an environmental factor that regulates fat storage. Proc Natl Acad Sci USA 2004; 101: 15718-15723

49 Schele E, Grahnemo L, Anesten F, Hallen A, Backhed F, Jansson JO. The gut microbiota reduces leptin sensitivity and the expression of the obesity-suppressing neuropeptides proglucagon $(\mathrm{Gcg})$ and brainderived neurotrophic factor (Bdnf) in the central nervous system. Endocrinology 2013; 154: 3643-3651

50 Everard A, Cani PD. Gut microbiota and GLP-1. Rev Endocr Metab Disord 2014; 15: 189-196

51 Everard A, Lazarevic V, Derrien M, Girard M, Muccioli GG, Neyrinck AM, Possemiers S, Van Holle A, Francois P, de Vos WM, Delzenne NM, Schrenzel J, Cani PD. Responses of gut microbiota and glucose and lipid metabolism to prebiotics in genetic obese and diet-induced leptin-resistant mice. Diabetes 2011; 60: 2775-2786

52 Cani PD, Amar J, Iglesias MA, Poggi M, Knauf C, Bastelica D, Neyrinck AM, Fava F, Tuohy KM, Chabo C, Waget A, Delmee E, Cousin B, Sulpice $T$, Chamontin B, Ferrieres J, Tanti JF, Gibson GR, Casteilla L, Delzenne NM, Alessi MC, Burcelin R. Metabolic endotoxemia initiates obesity and insulin resistance. Diabetes 2007; 56: 1761-1772

53 Requena T, Cotter P, Shahar DR, Kleiveland CR, Martinez-Cuesta MC, Pelaez $C$, Lea $T$. Interactions between gut microbiota, food and the obese host. Trends Food Sci Technol 2013; 34: 44-53

54 Backhed F, Manchester JK, Semenkovich CF, Gordon JI. Mechanisms underlying the resistance to diet-induced obesity in germ-free mice. Proc Natl Acad Sci USA 2007; 104: 979-984

55 Delgado S, Suarez A, Mayo B. Bifidobacterial diversity determined by culturing and by $16 \mathrm{~S}$ rDNA sequence analysis in feces and mucosa from ten healthy Spanish adults. Dig Dis Sci 2006; 51: 1878-1885

56 Mayorga Reyes L, Gonzalez Vazquez R, Cruz Arroyo SM, Melendez Avalos A, Reyes Castillo PA, Chavaro Perez DA, Ramos Terrones I, Ramos Ibanez N, Rodriguez Magallanes MM, Langella P, Bermudez Humaran $L$, Azaola Espinosa A. Correlation between diet and gut bacteria in a population of young adults. Int J Food Sci Nutr 2016; 1-9

57 Zhang C, Zhang M, Wang S, Han R, Cao Y, Hua W, Mao Y, Zhang X, Pang $X$, Wei C, Zhao G, Chen $Y$, Zhao L. Interactions between gut microbiota, host genetics and diet relevant to development of metabolic syndromes in mice. ISME J 2010; 4: 232-241

58 Hill C, Guarner F, Reid G, Gibson GR, Merenstein DJ, Pot B, Morelli L, Canani RB, Flint HJ, Salminen S, Calder PC, Sanders ME. Expert consensus document: The International Scientific Association for Probiotics and Prebiotics consensus statement on the scope and appropriate use of the term probiotic. Nat Rev Astroenterol Hepatol 2014; 11: 506-514
59 Kochan P, Chmielarczyk A, Szymaniak L, Brykczynski M, Galant K, Zych A, Pakosz K, Giedrys-Kalemba S, Lenouvel E, Heczko PB. Lactobacillus rhamnosus administration causes sepsis in a cardiosurgical patient-is the time right to revise probiotic safety guidelines? Clin Microbiol Infect 2011; 17: 1589-1592

60 Gibson GR, Scott KP, Rastall RA, Tuohy KM, Hotchkiss A, Dubert-Ferrandon $A$, Gareau M, Murphy EF, Saulnier D, Loh G, Macfarlane S, Delzenne N, Ringel Y, Kozianowski G, Dickmann R, Lenoir-Wijnkoop I, Walker C, Buddington R. Dietary prebiotics: current status and new definition. Food Sci Technol Bull Funct Foods 2010; 7: 1-19

61 Cani PD, Delzenne NM. The role of the gut microbiota in energy metabolism and metabolic disease. Curr Pharm Des 2009; 15: 15461558

62 Monteagudo-Mera A, Arthur JC, Jobin C, Keku T, Bruno-Barcena JM, Azcarate-Peril MA. High purity galacto-oligosaccharides enhance specific Bifidobacterium species and their metabolic activity in the mouse gut microbiome. Benef Microbes 2016; 1-18

63 Cani PD, Lecourt E, Dewulf EM, Sohet FM, Pachikian BD, Naslain D, De Backer F, Neyrinck AM, Delzenne NM. Gut microbiota fermentation of prebiotics increases satietogenic and incretin gut peptide production with consequences for appetite sensation and glucose response after a meal. Am J Clin Nutr 2009; 90: 1236-1243

64 Cani PD, Possemiers S, Van de Wiele T, Guiot Y, Everard A, Rottier $O$, Geurts L, Naslain D, Neyrinck A, Lambert DM, Muccioli GG, Delzenne NM. Changes in gut microbiota control inflammation in obese mice through a mechanism involving GLP-2-driven improvement of gut permeability. Gut 2009; 58: 1091-1103

65 Meyer D. Health benefits of prebiotic fibers. Adv Food Nutr Res 2015; 74: 47-91

66 Konturek PC, Haziri D, Brzozowski T, Hess T, Heyman S, Kwiecien S, Konturek SJ, Koziel J. Emerging role of fecal microbiota therapy in the treatment of gastrointestinal and extra-gastrointestinal diseases. J Physiol Pharmacol 2015; 66: 483-491

67 Vrieze A, Van Nood E, Holleman F, Salojarvi J, Kootte RS, Bartelsman JF, Dallinga-Thie GM, Ackermans MT, Serlie MJ, Oozeer R, Derrien M, Druesne A, Van Hylckama Vlieg JE, Bloks VW, Groen AK, Heilig HG, Zoetendal EG, Stroes ES, de Vos WM, Hoekstra JB, Nieuwdorp M. Transfer of intestinal microbiota from lean donors increases insulin sensitivity in individuals with metabolic syndrome. Gastroenterology 2012; 143: 913.e7-916.e7

68 Clemente JC, Ursell LK, Parfrey LW, Knight R. The impact of the gut microbiota on human health: an integrative view. Cell 2012; 148: $1258-1270$

69 Biagi E, Nylund L, Candela M, Ostan R, Bucci L, Pini E, Nikkila J, Monti $D$, Satokari $R$, Franceschi $C$, Brigidi $P$, De Vos $W$. Through ageing, and beyond: gut microbiota and inflammatory status in seniors and centenarians. PLoS One 2010; 5: e10667

70 Cardwell CR, Stene LC, Joner G, Cinek O, Svensson J, Goldacre MJ, Parslow RC, Pozzilli P, Brigis G, Stoyanov D, Urbonaite B, Sipetic S, Schober E, Ionescu-Tirgoviste C, Devoti G, de Beaufort CE, Buschard K, Patterson CC. Caesarean section is associated with an increased risk of childhood-onset type 1 diabetes mellitus: a meta-analysis of observational studies. Diabetologia 2008; 51: 726-735

71 Vehik $K$, Dabelea $D$. Why are C-section deliveries linked to childhood type 1 diabetes? Diabetes 2012; 61: 36-37

72 Davis-Richardson AG, Ardissone AN, Dias R, Simell V, Leonard MT, Kemppainen KM, Drew JC, Schatz D, Atkinson MA, Kolaczkowski B, Ilonen J, Knip M, Toppari J, Nurminen N, Hyoty $H$, Veijola R, Simell T, Mykkanen J, Simell O, Triplett EW. Bacteroides dorei dominates gut microbiome prior to autoimmunity in Finnish children at high risk for type 1 diabetes. Front Microbiol 2014; 5: 678

73 Chassaing B, Koren O, Goodrich JK, Poole AC, Srinivasan S, Ley RE, Gewirtz AT. Dietary emulsifiers impact the mouse gut microbiota promoting colitis and metabolic syndrome. Nature 2015; 519: 92-96

74 Suez J, Korem T, Zeevi D, Zilberman-Schapira G, Thaiss CA, Maza O, Israeli D, Zmora N, Gilad S, Weinberger A, Kuperman Y, Harmelin A, Kolodkin-Gal I, Shapiro H, Halpern Z, Segal E, Elinav E. Artificial sweeteners induce glucose intolerance by altering the gut microbiota. Nature 2014; 514: 181-186

75 Turnbaugh PJ, Backhed F, Fulton L, Gordon JI. Diet-induced obesity is linked to marked but reversible alterations in the mouse distal gut microbiome. Cell Host Microbe 2008; 3: 213-223

76 Karlsson FH, Tremaroli V, Nookaew I, Bergstrom G, Behre CJ, Fagerberg $B$, Nielsen J, Backhed F. Gut metagenome in European women with normal, impaired and diabetic glucose control. Nature 2013; 498: 99-103 
77 Sato J, Kanazawa A, Ikeda F, Yoshihara T, Goto H, Abe H, Komiya K, Kawaguchi M, Shimizu T, Ogihara T, Tamura Y, Sakurai Y, Yamamoto $R$, Mita T, Fujitani Y, Fukuda H, Nomoto K, Takahashi T, Asahara T, Hirose T, Nagata S, Yamashiro Y, Watada H. Gut dysbiosis and detection of "live gut bacteria" in blood of Japanese patients with type 2 diabetes. Diabetes Care 2014; 37: 2343-2350

78 Schwiertz A, Taras D, Schafer K, Beijer S, Bos NA, Donus C, Hardt PD. Microbiota and SCFA in lean and overweight healthy subjects. Obesity (Silver Spring) 2010; 18: 190-195

79 Zhang X, Shen D, Fang Z, Jie Z, Qiu X, Zhang C, Chen Y, Ji L. Human gut microbiota changes reveal the progression of glucose intolerance. PLoS One 2013; 8: e71108

80 Cani PD, Knauf C, Iglesias MA, Drucker DJ, Delzenne NM, Burcelin R. Improvement of glucose tolerance and hepatic insulin sensitivity by oligofructose requires a functional glucagon-like peptide 1 receptor. Diabetes 2006; 55: 1484-1490

81 De Angelis M, Montemurno E, Vannini L, Cosola C, Cavallo N, Gozzi G, Maranzano V, Di Cagno R, Gobbetti M, Gesualdo L. Effect of WholeGrain Barley on the Human Fecal Microbiota and Metabolome. Appl Environ Microbiol 2015; 81: 7945-7956

82 Tazoe H, Otomo Y, Kaji I, Tanaka R, Karaki SI, Kuwahara A. Roles of short-chain fatty acids receptors, GPR41 and GPR43 on colonic functions. J Physiol Pharmacol 2008; 59 (Suppl 2): 251-262

83 Kimura I, Ozawa K, Inoue D, Imamura T, Kimura K, Maeda T, Terasawa K, Kashihara D, Hirano K, Tani T, Takahashi T, Miyauchi S, Shioi G, Inoue $H$, Tsujimoto $G$. The gut microbiota suppresses insulin-mediated fat accumulation via the short-chain fatty acid receptor GPR43. Nat Commun 2013; 4: 1829

84 Oh DY, Lagakos WS. The role of G-protein-coupled receptors in mediating the effect of fatty acids on inflammation and insulin sensitivity. Curr Opin Clin Nutr Metab Care 2011; 14: 322-327

85 Esser N, Legrand-Poels S, Piette J, Scheen AJ, Paquot N. Inflammation as a link between obesity, metabolic syndrome and type 2 diabetes. Diabetes Res Clin Pract 2014; 105: 141-150

86 Yassour M, Lim MY, Yun HS, Tickle TL, Sung J, Song YM, Lee K, Franzosa EA, Morgan XC, Gevers D, Lander ES, Xavier RJ, Birren BW, Ko G, Huttenhower $C$. Sub-clinical detection of gut microbial biomarkers of obesity and type 2 diabetes. Genome Med 2016; 8: 17

87 Shoelson SE, Lee J, Goldfine AB. Inflammation and insulin resistance. J Clin Invest 2006; 116: 1793-1801

88 Cani PD, Bibiloni R, Knauf C, Waget A, Neyrinck AM, Delzenne NM, Burcelin R. Changes in gut microbiota control metabolic endotoxemia-induced inflammation in high-fat diet-induced obesity and diabetes in mice. Diabetes 2008; 57: 1470-1481

89 De Vadder F, Kovatcheva-Datchary P, Goncalves D, Vinera J, Zitoun C, Duchampt A, Backhed F, Mithieux G. Microbiota-generated metabolites promote metabolic benefits via gut-brain neural circuits. Cell 2014; 156: 84-96

90 Delaere F, Duchampt A, Mounien L, Seyer P, Duraffourd C, Zitoun C, Thorens B, Mithieux $G$. The role of sodium-coupled glucose co-transporter 3 in the satiety effect of portal glucose sensing. Mol Metab 2012; 2: 47-53

91 Ejtahed HS, Mohtadi-Nia J, Homayouni-Rad A, Niafar M, AsghariJafarabadi $M$, Mofid $V$. Probiotic yogurt improves antioxidant status in type 2 diabetic patients. Nutrition 2012; 28: 539-543

92 Ejtahed HS, Mohtadi-Nia J, Homayouni-Rad A, Niafar M, AsghariJafarabadi M, Mofid V, Akbarian-Moghari A. Effect of probiotic yogurt containing Lactobacillus acidophilus and Bifidobacterium lactis on lipid profile in individuals with type 2 diabetes mellitus. J Dairy Sci 2011; 94: 3288-3294

93 Prasad J, Gill HS, Smart JB, Gopal PK. Selection and characterization of Lactobacillus and Bifidobacterium strains for use as probiotics. Int Dairy J 1998; 8: 993-1002

94 Yadav H, Jain S, Sinha PR. Antidiabetic effect of probiotic dahi containing Lactobacillus acidophilus and Lactobacillus casei in high fructose fed rats. Nutrition 2007; 23: 62-68

95 Andersson U, Branning C, Ahrne S, Molin G, Alenfall J, Onning G, Nyman $M$, Holm C. Probiotics lower plasma glucose in the high-fat fed C57BL/6J mouse. Benef Microbes 2010; 1: 189-196

96 Marques TM, Patterson E, Wall R, O'Sullivan O, Fitzgerald GF, Cotter $P D$, Dinan TG, Cryan JF, Ross RP, Stanton C. Influence of GABA and GABA-producing Lactobacillus brevis DPC 6108 on the development of diabetes in a streptozotocin rat model. Benef Microbes 2016; 1-12

97 Pickup JC. Inflammation and activated innate immunity in the pathogenesis of type 2 diabetes. Diabetes Care 2004; 27: 813-823

98 Razmpoosh E, Javadi M, Ejtahed HS, Mirmiran P. Probiotics as beneficial agents in the management of diabetes mellitus: a systematic review. Diabetes Metab Res Rev 2016; 32: 143-168
99 Cani PD, Neyrinck AM, Fava F, Knauf C, Burcelin RG, Tuohy KM, Gibson $G R$, Delzenne NM. Selective increases of bifidobacteria in gut microflora improve high-fat-diet-induced diabetes in mice through a mechanism associated with endotoxaemia. Diabetologia 2007; 50: 2374-2383

100 Shin NR, Lee JC, Lee HY, Kim MS, Whon TW, Lee MS, Bae JW. An increase in the Akkermansia spp. population induced by metformin treatment improves glucose homeostasis in diet-induced obese mice. Gut 2014; 63: 727-735

101 Yin YY, Liu YJ, Zhu WY, Mao SY. Effects of Acarbose Addition on Ruminal Bacterial Microbiota, Lipopolysaccharide Levels and Fermentation Characteristics In vitro. Asian-Australas J Anim Sci 2014; 27: 1726-1735

102 Sambrook P, Cooper C. Osteoporosis. Lancet 2006; 367: 2010-2018

103 Ralston SH, Uitterlinden AG. Genetics of osteoporosis. Endocr Rev 2010; 31: 629-662

104 Maynard CL, Elson CO, Hatton RD, Weaver CT. Reciprocal interactions of the intestinal microbiota and immune system. Nature 2012; 489: 231-241

105 Goulet 0 . Potential role of the intestinal microbiota in programming health and disease. Nutr Rev 2015; 73 (Suppl 1): 32-40

106 Schmidt S, Mellstrom D, Norjavaara E, Sundh V, Saalman R. Longitudinal assessment of bone mineral density in children and adolescents with inflammatory bowel disease. J Pediatr Gastroenterol Nutr 2012; 55: 511-518

107 Lorenzo J, Horowitz M, Choi Y. Osteoimmunology: interactions of the bone and immune system. Endocr Rev 2008; 29: 403-440

108 Ohlsson C, Sjogren K. Effects of the gut microbiota on bone mass. Trends Endocrinol Metab 2015; 26: 69-74

109 Inglis JE, Ilich JZ. The Microbiome and Osteosarcopenic Obesity in Older Individuals in Long-Term Care Facilities. Curr Osteoporos Rep 2015; 13: 358-362

110 van Tongeren SP, Slaets JP, Harmsen HJ, Welling GW. Fecal microbiota composition and frailty. Appl Environ Microbiol 2005; 71: 64386442

111 Claesson MJ, Jeffery IB, Conde S, Power SE, O'Connor EM, Cusack S, Harris HM, Coakley M, Lakshminarayanan B, O'Sullivan O, Fitzgerald GF, Deane J, O'Connor M, Harnedy N, O'Connor K, O'Mahony D, van Sinderen D, Wallace M, Brennan L, Stanton C, Marchesi JR, Fitzgerald $A P$, Shanahan F, Hill C, Ross RP, O'Toole PW. Gut microbiota composition correlates with diet and health in the elderly. Nature 2012; 488: 178-184

112 Charles JF, Ermann J, Aliprantis AO. The intestinal microbiome and skeletal fitness: Connecting bugs and bones. Clin Immunol 2015; 159: $163-169$

113 Weaver CM, Martin BR, Nakatsu CH, Armstrong AP, Clavijo A, McCabe LD, McCabe GP, Duignan S, Schoterman MH, van den Heuvel EG. Galactooligosaccharides improve mineral absorption and bone properties in growing rats through gut fermentation. J Agric Food Chem 2011; 59: 6501-6510

114 Clarke G, Stilling RM, Kennedy PJ, Stanton C, Cryan JF, Dinan TG. Minireview: Gut microbiota: the neglected endocrine organ. Mol Endocrinol 2014; 28: 1221-1238

115 Reigstad CS, Salmonson CE, Rainey JF 3rd, Szurszewski JH, Linden DR, Sonnenburg JL, Farrugia G, Kashyap PC. Gut microbes promote colonic serotonin production through an effect of short-chain fatty acids on enterochromaffin cells. FASEB J 2015; 29: 1395-1403

116 Yano JM, Yu K, Donaldson GP, Shastri GG, Ann P, Ma L, Nagler CR, Ismagilov RF, Mazmanian SK, Hsiao EY. Indigenous bacteria from the gut microbiota regulate host serotonin biosynthesis. Cell 2015; 161: 264-276

117 Scholz-Ahrens KE, Schaafsma G, van den Heuvel EG, Schrezenmeir J. Effects of prebiotics on mineral metabolism. Am J Clin Nutr 2001; 73 (2 Suppl): 459s-464s

118 Britton RA, Irwin R, Quach D, Schaefer L, Zhang J, Lee T, Parameswaran $N$, McCabe LR. Probiotic L. reuteri treatment prevents bone loss in a menopausal ovariectomized mouse model. J Cell Physiol 2014; 229: $1822-1830$

119 Ohlsson C, Engdahl C, Fak F, Andersson A, Windahl SH, Farman HH, Moverare-Skrtic S, Islander $U$, Sjogren K. Probiotics protect mice from ovariectomy-induced cortical bone loss. PLoS One 2014; 9: e92368

120 McCabe LR, Irwin R, Schaefer L, Britton RA. Probiotic use decreases intestinal inflammation and increases bone density in healthy male but not female mice. J Cell Physiol 2013; 228: 1793-1798

121 Zhang J, Motyl KJ, Irwin R, MacDougald OA, Britton RA, McCabe LR. Loss of bone and Wnt $10 \mathrm{~b}$ expression in male type 1 diabetic mice is blocked by the probiotic L. reuteri. Endocrinology 2015 En20151308 
122 Rodrigues FC, Castro AS, Rodrigues VC, Fernandes SA, Fontes EA, de Oliveira TT, Martino HS, de Luces Fortes Ferreira CL. Yacon flour and Bifidobacterium longum modulate bone health in rats. J Med Food 2012; 15: 664-670

123 Hasani-Ranjbar S, Jouyandeh Z, Abdollahi M. A systematic review of anti-obesity medicinal plants - an update. J Diabetes Metab Disord 2013; $12: 28$

124 Hasani-Ranjbar S, Larijani B. Medicinal plants as potential new target drugs in endocrine disorders - Review article. Iran J Public Health 2014; 43 (Suppl 1): 24-34
125 Hasani-Ranjbar S, Nayebi N, Larijani B, Abdollahi M. A systematic review of the efficacy and safety of herbal medicines used in the treatment of obesity. World J Gastroenterol 2009; 15: 3073-3085

126 Neef A, Sanz Y. Future for probiotic science in functional food and dietary supplement development. Curr Opin Clin Nutr Metab Care 2013; 16: 679-687 